\title{
Identifying important endemic areas using ecoregions: birds and mammals in the Indo-Pacific
}

\author{
Julia E. Fa, Robert W. Burn, Mark R. Stanley Price and Fiona M. Underwood
}

\begin{abstract}
Concentrations of large numbers of endemic species have been singled out in prioritization exercises as significant areas for global biodiversity conservation. This paper describes bird and mammal endemicity in Indo-Pacific ecoregions. An ecoregion is a relatively large unit of land or water that contains a distinct assemblage of natural communities. We prioritize 133 ecoregions according to their levels of endemicity, and explain how variables such as biome type, whether the ecoregion is on an island or continental mass, montane or nonmontane, correlate with the proportion of the total species assemblage that are endemic. Following an exploratory principal components analysis we classify all ecoregions according to the relationship between numbers of endemics and overall species richness. Endemicity is negatively correlated with species richness. We show that plotting the logit transformation of the
\end{abstract}

endemicity of birds and mammals against log of species richness is a more effective and useful way of identifying important ecoregions than simply ordering ecoregions by the proportion of endemic species, or any other single measure. The plot, divided into 16 regions corresponding to the quartiles of the two variables, was used to identify ecoregions of high conservation value. These are the ecoregions with the highest endemicity and lowest species richness. Further analysis shows that island and montane ecoregions, regardless of their biome type, are by far the most important for endemic species.

Keywords Birds, ecoregions, endemic species, IndoPacific region, mammals.

This paper contains supplementary material that can only be found online at http:/ / journals.cambridge.org

\section{Introduction}

Growing awareness of the unprecedented decline in global biodiversity has stimulated new national and international programmes. A variety of approaches are being used by government agencies, donor institutions and non-governmental organizations for prioritizing actions by identifying ecosystems, habitats, or species most important to conservation goals (Johnson, 1995). Priorities reflect value judgements. Most efforts are guided by the consideration that biodiversity is unevenly distributed worldwide. International approaches for setting geographic priorities have assumed that using the number of species (and sometimes the degree of endemism) is the most effective way to broadly

Julia E. Fa (Corresponding author) Mark R. Stanley Price Durrell Wildlife Conservation Trust, Les Augrès Manor, Trinity, Jersey, JE3 5BP, UK. E-mail jfa@durrell.org

Robert W. Burn Statistical Services Centre, Harry Pitt Building, University of Reading, PO Box 240, Whiteknights Road, Reading, RG6 6FN, UK.

Fiona M. Underwood Research Unit for Wildlife Population Assessment, University of St Andrews, The Observatory, Buchanan Gardens, St Andrews, Fife, KY16 9LZ, UK.

Received 28 January 2003. Revision requested 2 May 2003. Accepted 23 June 2003. distinguish conservation priorities between countries or regions. Species richness is a commonly utilized criterion for assigning conservation priority (Johnson, 1995; Mittermeier et al., 1998) as a function of site richness (alpha diversity) and the rate at which species replace one another between sites (beta diversity) (Fjeldså \& Rahbek, 1997; Wikramanayake et al., 1998). However, local patterns of richness and rarity across taxa are often unrelated (Pearson \& Cassola, 1992; Prendergast, 1997; Oliver et al. 1998; Fjeldså et al., 1999a; Jetz \& Rahbek, 2002).

It has been argued that a further conservation priority is the need to preserve evolutionary processes (Erwin, 1991; Vane-Wright et al., 1991), but it is difficult to translate this into conservation action because it has been difficult to identify evolutionary hotspots (Spector, 2002). However, the presence of a high proportion of endemic species, taxa that have evolved in and are restricted to a particular area, denotes areas responsible for the origination of evolutionary novelty (Balmford et al., 1998). This is currently the emphasis of triage exercises undertaken by organizations such as Conservation International and BirdLife International. The distribution of endemics was mapped as early as the 1960s and more recently using sophisticated computer methods (Williams \& Humphries, 1996; de Klerk et al., 2002). 
Recent phylogeographic approaches (mostly molecular studies) for defining hotspots and dynamics of speciation in the tropics (e.g. Arctander et al., 1999; García-Moreno \& Fjeldså, 2000) show that endemism is often locally aggregated and most speciation occurs by relict isolation. However, most maps of endemism simply paint pictures of species concentrations rather than adequately defining which geographical units to work on. Conservation decisions for action must refer to a finer geographical scale than discussed by analyses of global biodiversity hotspots (Myers et al., 2000) or Endemic Bird Areas (Stattersfield et al., 1998). Some of these analyses have also being criticised for their inability to establish conservation priorities at regional, national or sub-national levels (Dinerstein \& Wikramanayake, 1993). There is a need for new techniques that allow analyses to move freely between different scales so that global analyses can be translated into effective conservation action (Mace et al., 2000).

In this paper we analyse data on endemic bird and mammal species and species richness within ecoregions in the Indo-Pacific (Wikramanayake et al., 2002). An ecoregion is defined as a relatively large unit of land or water within which there are a similar set of encounter probabilities for different biodiversity features, whether they are species or communities (Olson et al., 2001; Olson, pers. comm.). The method used for delimiting IndoPacific ecoregions by Wikramanayake et al. (2002) first denotes biomes, then major vegetation types or perceived communities on the basis of major environmental patterns, then montane versus lowland, followed by distinctive communities of species. In some cases historical factors were given higher priority than climatic features, e.g. the presence and absence of land bridges were used in refining boundaries for Phillipines ecoregions. We use the data to answer two questions. Firstly, how can we characterize ecoregions, using numbers of endemics and non-endemics, so that ecoregions of greater importance as generators of unique taxa can be easily identified? Secondly, how does the characterization based on numbers of endemics and non-endemics relate to characterizations of the ecoregions by isolation, area of ecoregion and biome type?

\section{Methods}

\section{Geographical scope}

Our study area, the Indo-Pacific, encompasses South and South-east Asia, through the Indonesian and Philippine archipelagos to New Caledonia and Vanuatu in the South Pacific (Wikramanayake et al., 2002a). China and west Asia are excluded and thus the northern boundary along the Himalayas and Indochina is an artificial boundary, as is the western boundary between Pakistan, Afghanistan and Iran. The Torres Straits between New Guinea and northern Australia, which represents a floral transition zone, delimits the eastern boundary of the study region.

Biologically the Indo-Pacific region, which is divisible into 140 ecoregions, is very rich as the result of numerous dispersal barriers that concentrate species in small areas. Each ecoregion is classified by biome type. A biome is a major regional group of distinctive plants and animals, discernible at a global scale (e.g. temperate forest, tropical rainforest). Ten biomes are distinguished for the region, corresponding to a global framework applied to other regional analyses (Dinerstein et al., 1995; Olson \& Dinerstein, 1998; Ricketts et al., 1999; Olson et al., 2001). A large number of continental ecoregions are covered by tropical dry forest, desert, thorn scrub and subtropical broadleaf forest. The Indian subcontinent and Indochina contain vast dry forest ecoregions in the Deccan Plateau, the Irrawaddy River plains and central Indochina, flanked by montane moist forests along the north-south lying mountain ranges. Most of the archipelago ecoregions are tropical moist forest, with lowland forest surrounding montane moist forests. Montane ecoregions are described as areas found at $>1,000 \mathrm{~m}$.

\section{Sources of data}

Each Indo-Pacific ecoregion was characterized (Wikramanayake et al., 2002a) in terms of: (1) all bird species, (2) endemic bird species, (3) all mammal species, and (4) endemic mammal species. An endemic species was regarded as a taxon that only occurred within a single ecoregion. Only 133 of 140 ecoregions were included because species information was not available for the seven mangrove ecoregions. The data includes the area of each ecoregion (in $\mathrm{km}^{2}$ ) and biome type. Biome types were further ordered into four main groups: (1) tropical/ subtropical forests - moist and dry broadleaf forests, coniferous forests; (2) temperate forests - broadleaf and mixed forests, coniferous forests; (3) grasslands, savannas and shrublands - flooded grasslands and savannas, montane grasslands, shrublands; (4) deserts and xeric shrublands. Two additional variables were indicators of the degree of geographic isolation: whether the ecoregion was situated on an island or continental area and whether or not it was montane. For islands only, we measured distance to the nearest continental mass.

\section{Statistical analyses}

To characterize the ecoregions a principal components analysis (PCA) was carried out on the log-transform 
$(\log (x+1)$; used because of the highly skewed distributions) of the numbers of endemic and non-endemic bird and mammal species. This analysis suggested two measures, endemicity and species richness, that could be used simultaneously to characterize the ecoregions. A plot of these two measures and the division of the ecoregions into quartile ranges for each measure were used to classify the ecoregions into 16 groups. Quartile ranges were calculated separately for the two measures. For example, for species richness, the ecoregions were ordered from lowest to highest value. The first quartile is the species richness below which $25 \%$ of the ecoregions fall, in this case between the ecoregions in 33rd and 34th position on the list. The second quartile is the median value of species richness for all ecoregions.

Generalized linear models (McCullagh \& Nelder, 1989) were used to assess the importance of variables that describe the ecoregions with respect to each of the measures suggested by the PCA. The explanatory variables used in our analyses were: a) biome group, b) ecoregion size, c) island/continental, d) montane/nonmontane, and e) distance from continent (for islands only). We first fitted a maximal model containing all variables and then used a stepwise procedure to eliminate redundancies. The algorithm used was the stepwise AIC method provided by Venables \& Ripley (1999) for the S-PLUS software (Insightful Corp., 2001). We employed binomial logistic regression models (McCullagh \& Nelder, 1989; Collett, 2002) to assess which ecoregion variables correlated with the proportion of endemic species. For species richness, the natural analysis would be to fit Poisson regression models (McCullagh \& Nelder, 1989). For both measures however, diagnostic checks of initial attempts at fitting these models indicated severe overdispersion in the dataset (i.e. variance greater than expected under the assumed model). Causes of overdispersion and ways of compensating for this are discussed in Collett (2002). Our approach was to fit models with a dispersion parameter estimated from the data, so that the variance function was a multiple of the usual variance. This was accomplished by fitting quasi-likelihood models (McCullagh \& Nelder, 1989).
The version of the generalized $R^{2}$ statistic used as an informal indication of the usefulness of logistic regression models fitted was the one preferred by Menard (2000). Model adequacy was assessed by standard graphical methods of inspecting residuals. Statistical analyses were performed using the S-PLUS system (Insightful Corp., 2001).

\section{Results}

\section{General characteristics of ecoregions}

Of the 133 ecoregions used in our analyses, 79 were found in continental regions (i.e. Indian Subcontinent and Indochina) and 54 in archipelagic regions (Sunda Shelf and Philippines, Wallacea, and New Guinea and Melanesia). Five of the ecoregions in the continental regions are also islands (three ecoregions in Sri Lanka and the Andaman and Nicobar groups). Continental ecoregions were on average larger (mean area $=83,772$ $\left.\pm \mathrm{SD} 96,101 \mathrm{~km}^{2}\right)$ than island ecoregions $(52,190$ $\pm 78,717 \mathrm{~km}^{2}$ ) and montane ecoregions were smaller $\left(42,168 \pm 44,367 \mathrm{~km}^{2}\right)$ than non-montane ecoregions $\left(74,662 \pm 95,332 \mathrm{~km}^{2}\right)$. Other general characteristics of the ecoregions classified by biome group are summarized in Table 1.

For both mammals and birds, species richness (numbers of species per $100 \mathrm{~km}^{2}$ ) was similar in all biome groups except for desert ecoregions, where richness was considerably lower (Fig. 1a). Overall, mammal species richness (mean $=0.38 \pm \mathrm{SD} 0.64$ ) was lower than that of birds $(1.31 \pm 1.66)$. Percentage endemism, however, was higher for mammals $(9.44 \pm 13.78)$ than for birds $(5.65 \pm 8.91)$. Endemism was found to be more variable, for both mammals and birds, between ecoregions in tropical forests than in other biome group (Fig. 1b).

\section{Identifying important ecoregions}

The first two components of the PCA accounted for $91.2 \%$ of the variation in the data. The component loadings (Table 2) indicate that the first component

Table 1 Profiles of the ecoregion data, with the characteristics of each biome group. Note that the majority of the ecoregions fall in the tropical and subtropical forest biome group.

\begin{tabular}{llllll}
\hline & \multicolumn{2}{l}{ Biome group } & & & \\
\cline { 2 - 5 } Characteristic & $\begin{array}{l}\text { Tropical \& } \\
\text { subtropical forests }\end{array}$ & Temperate forests & $\begin{array}{l}\text { Grasslands, savannas } \\
\& \text { shrublands }\end{array}$ & $\begin{array}{l}\text { Deserts \& xeric } \\
\text { shrublands }\end{array}$ & Overall \\
\hline No. of ecoregions & 109 & 6 & 11 & 7 & 133 \\
Mean area $\pm S D\left(\mathrm{~km}^{2}\right)$ & $65,760( \pm 81,240)$ & $37,167( \pm 28,781)$ & $34,191( \pm 28,849)$ & $206,900( \pm 173,936)$ & $69,287( \pm 89,630)$ \\
No. montane & 20 & 1 & 1 & 0 & 22 \\
No. islands & 58 & 0 & 3 & 0 & 61 \\
\hline
\end{tabular}


(a)
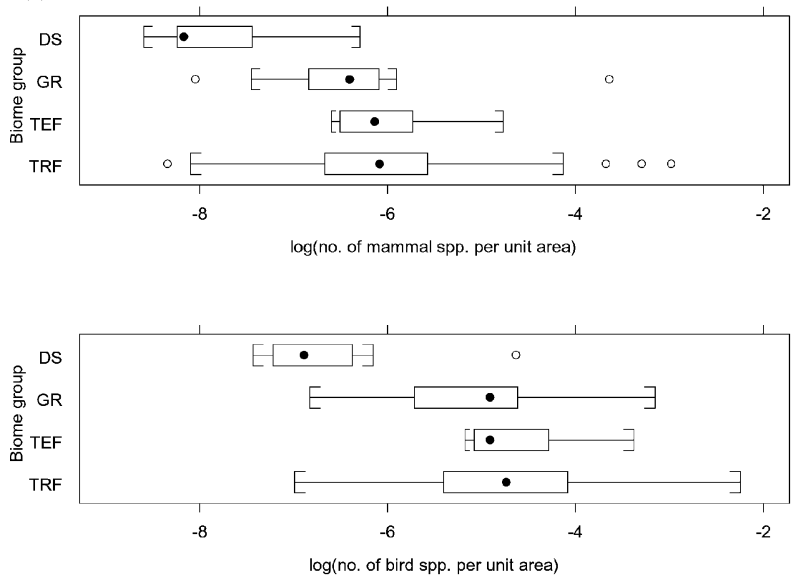

(b)
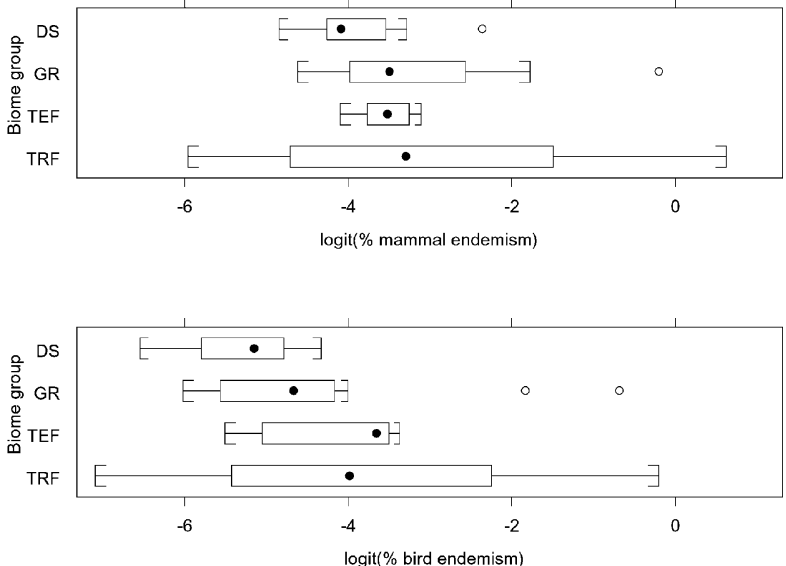

Fig. 1 Box-plots of species richness (a) and percentage endemism (b) by biome group (see text for details) for mammals and birds. DS, deserts and xeric shrublands; GR, grasslands, savannas and shrublands; TEF, temperate forests; TRF, tropical and subtropical forests.

Table 2 Principal component loadings, i.e. coefficients of the four original variables in the first two principal components.

\begin{tabular}{lcl}
\hline Variable & Component 1 & Component 2 \\
\hline Endemic mammals & -0.558 & 0.277 \\
Endemic birds & -0.791 & 0.104 \\
Non-endemic mammals & 0.217 & 0.762 \\
Non-endemic birds & 0.124 & 0.576 \\
\hline
\end{tabular}

(71.7\% of the variation) predominantly represents endemicity (negatively directed). The second component (19.5\% of the variation) is essentially a measure of overall species richness. This interpretation is confirmed by the biplot (Krzanowski, 1988) of the PCA component scores together with the original variables (Fig. 2). Ecoregions on the left of the biplot have high endemicity whereas those on the right have low endemicity. Ecoregions in a

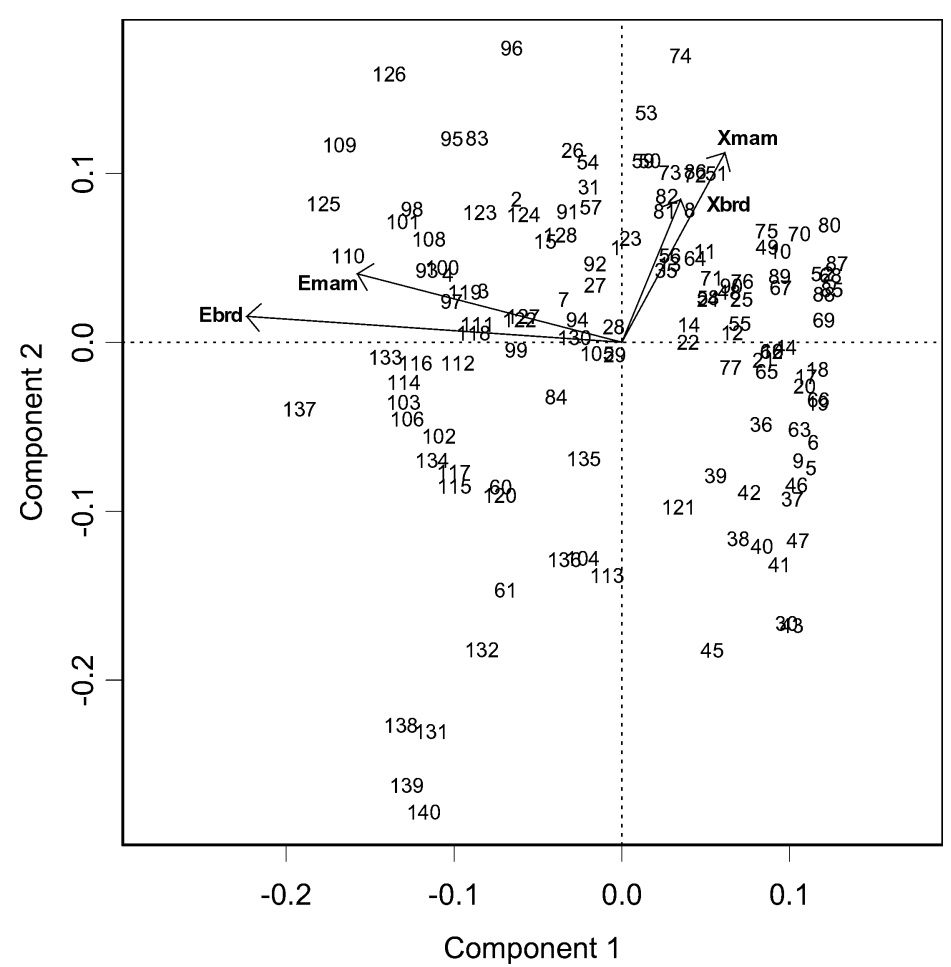

Fig. 2 Biplot of components 1 and 2 of the principal components analysis. The numbered points are the ecoregions. The arrows represent the original variables and their lengths are a relative measure of their contribution to the overall variability in the data. The perpendicular projections of the arrows onto the component axes are the loadings of the corresponding variables. Emam, endemic mammals; Ebrd, endemic birds; Xmam, non-endemic mammals; Xbrd, non-endemic birds. 
near-vertical line on the right-hand side of the biplot are those with no endemic species. Species richness increases from the bottom to the top of the biplot. The arrows representing the numbers of non-endemics are nearly parallel to the second component axis, reflecting the fact that overall species richness consists mainly of nonendemics, as the number of endemics is small compared to the large numbers of non-endemics. The biplot also shows that numbers of endemic mammal and bird species are highly correlated, as the angle between the lines representing these two variables is small, suggesting that important areas for endemicity are similar for both birds and mammals.

Given the clear interpretation of the first two components, we suggest a simple method for identifying important ecoregions that avoids the need for principal components analysis. The first component in the PCA is predominantly a contrast between the numbers of endemic and non-endemic species. Because the input variables for the PCA were on a log scale, a simple measure of endemicity that would be consistent with the results of the PCA is:

$$
\log (E)-\log (S-E)=\log \left(\frac{E}{S-E}\right)
$$

where $E=$ number of endemic species and $S=$ number of species. This is the logit transformation (Collett, 2002) of the proportion of endemic species. To avoid difficulties with cases where $E=0$, it is customary to make a small adjustment to the logit transformation and define the empirical logit as:

$\log \left(\frac{E+0.5}{S-E+0.5}\right)$

As the proportion of endemics in the ecoregion increases so the empirical logit increases. A negative score indicates that less than half the species are endemics. The empirical logit for the Indo-Pacific data, for birds and mammals combined, is less than zero. By similar reasoning, $\log (S)$ is suggested by the second component. A plot of the empirical logit against $\log (S)$ (Fig. 3) is broadly similar to the PCA component plot.

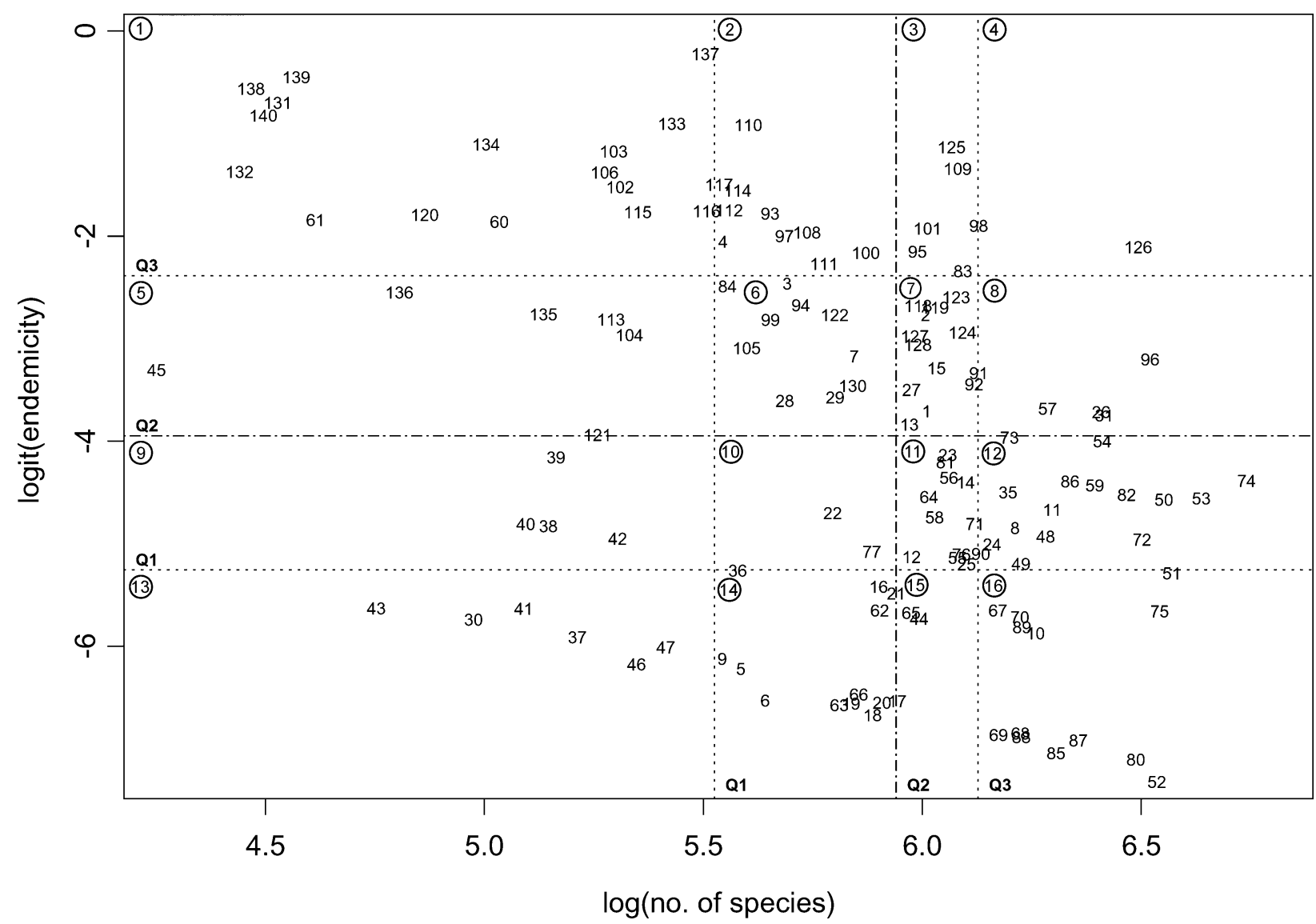

Fig. 3 Plot of numbered ecoregions (see Appendix) by logit(endemicity) and $\log$ (species richness). Q1 = 1st quartile, $\mathrm{Q} 2=$ median, $\mathrm{Q} 3=3$ rd quartile. 
This plot (Fig. 3) can be used to identify important ecoregions. For example, the upper left quadrant contains ecoregions with relatively high endemicity and low species richness. Refining this further, we can identify those ecoregions in the upper quartile range of the endemicity measure and the lower quartile range of the richness measure. This can be extended to a classification of ecoregions according to where they fall within each of the 16 combinations of ranges defined by the quartiles for each of the two component scores (Group id., Appendix). A map of the ecoregions classified according to the logit transformation of the bird and mammal endemism data are shown in Fig 4. The 10 most important ecoregions according to our classification were: (1) Solomon Islands rainforests, (2) Vanuatu rainforests, (3) New Caledonia rainforests, (4) New Guinea Central Range sub-alpine grasslands, (5) New Caledonia dry forests, (6) New Britain-New Ireland lowland rainforests, (7) New Britain-New Ireland montane rainforests, (8) Mindanao montane rainforests, (9) Admiralty Islands lowland rainforests, and (10) Luzon tropical pine forests. Bird and mammal endemics found in the highest endemicity group (group, Appendix) represented 33 and 21\% (29\% combined) of the total number of endemics in the Indo-Pacific. In terms of land area covered, the highest endemicity ecoregions accounted for $2 \%\left(193,300 \mathrm{~km}^{2}\right)$ of the total 9.2 million $\mathrm{km}^{2}$.

\section{Characterising endemicity and species richness}

Mean endemism for the four biome groups shows considerable variation, with tropical forests having the highest variability (Fig. 1b). However, fitting an overdispersed binomial logistic regression model to both the mammal and the bird data demonstrates that this between-biome variation is accounted for by the variables island vs continent, distance from continent and montane vs non-montane. Diagnostic residual plots were satisfactory. For mammals (Table 3), the overwhelmingly dominant effect is island vs continent, and distance from a continent is also important. For birds (Table 3), the effects of island vs continent and distance are similar to their effect on mammal endemicity, but montane vs non-montane also has a significant effect.

Thus, the characteristics of ecoregions that are most strongly associated with high rates of endemicity are those that indicate isolation. There are proportionately more endemic species of birds and mammals on islands and in montane regions (Fig. 5). On islands, the proportion of endemics tends to increase with distance from continents. The analysis shows that once these factors are accounted for, differences in endemicity between biome types are negligible.

As expected, total number of mammal and bird species (S) was positively correlated with area of ecoregion:
$R^{2}=0.33$ for $\log (S)$ vs $\log$ (area). Analysis of the effect of other factors on species richness per unit area, by fitting an overdispersed Poisson regression model, indicated that only biome group was significantly associated $(F=4.39, \mathrm{df}=3,129, \mathrm{P}=0.006)$. The box-plots in Fig. $1 \mathrm{~b}$ indicate that the dominant contribution to the overall difference among biome groups is the low number for deserts. Non-significant variables in the model were: island vs continent $(\mathrm{P}=0.97)$, distance from continent $(\mathrm{P}=0.34)$ and montane vs non-montane $(\mathrm{P}=0.12)$. Thus, unlike endemicity, it is biome type (desert vs others) that is most strongly associated with species richness; isolation appears to be relatively unimportant.

\section{Discussion}

Techniques for choosing areas for conservation have become increasingly sophisticated. A variety of methods are available for determining which areas should be conserved first, using criteria such as representativeness or complementarity (Williams, 1998). Such methods apply rules to determine priorities consistent with values and goals for in situ conservation, with most of the techniques requiring species counts within grid-cell maps. However, despite the potential of these procedures, few are currently used to guide conservation action. For example, even the most widely publicized method of biodiversity hotspots (Myers, 1988, 1990; Myers et al., 2000) is loosely based on 'biological commonalities' of the areas concerned. Consequently, hotspots are large, broadly delineated regions covering various biological units, making it difficult to determine the locations of clusters of endemic species (e.g. Medail \& Quezel, 1997, 1998).

Numerical analyses of concentrations of rare or endemic species have provided insights into speciation patterns (Fjeldså et al., 1997) but their value in pinpointing priority areas diminishes relative to the resolution of the grid-cell maps used. Larger grid cells make it more difficult to delineate areas where the species are found, although analyses of data in $15^{\circ}$ grid cells give a resolution that is similar to the ecoregion approach (Fjeldså, 2000 , 2002). However, a biologically meaningful way to delineate concentrations of unique taxa must involve the definition of landscape units within which the taxa evolved. Such areas, often created through the presence of geographical barriers, are disproportionately responsible for endemics, and have been described as 'speciation machines' (Rosenweig, 1995) or 'species factories' (Balmford et al., 1998). This corresponds to the important role that geographical isolation plays in species development and maintenance, even though the relative importance of the various processes that produce new species, such as natural versus sexual selection, remains 


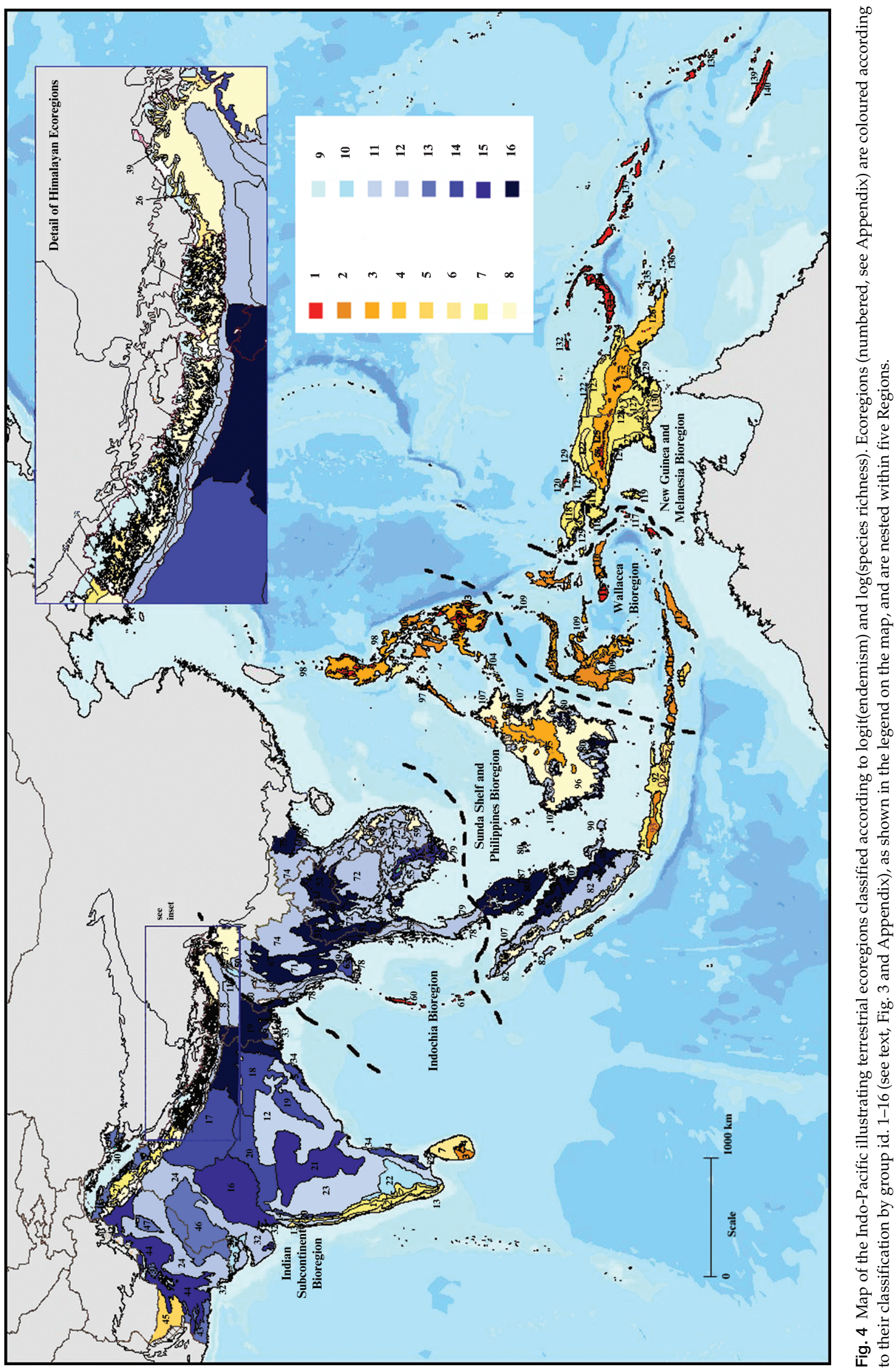


Table 3 Significant explanatory variables in the logistic regression analysis, accounting for overdispersion, for endemicity of mammals ${ }^{1}$ and birds ${ }^{2}$

\begin{tabular}{lcrrrrr}
\hline Variable & Coefficient $^{3}$ & SE & Deviance d.f. & $\mathrm{P}^{4}$ \\
\hline $\begin{array}{l}\text { Mammals } \\
\text { Island vs continental }\end{array}$ & 0.83 & 0.15 & 166.8 & 1 & $<0.0001$ \\
$\begin{array}{l}\text { Distance } \\
\text { Birds }\end{array}$ & 0.06 & 0.01 & 83.8 & 1 & 0.0001 \\
Island vs continental & 0.94 & 0.17 & 408.0 & 1 & $<0.0001$ \\
$\begin{array}{l}\text { Distance } \\
\text { Montane vs }\end{array}$ & 0.05 & 0.01 & 233.3 & 1 & $<0.0001$ \\
non-montane & -0.25 & 0.10 & 64.5 & 1 & 0.02 \\
\hline
\end{tabular}

${ }^{1}$ Overall $R^{2}=0.53 ; \mathrm{P}=0.08$ for montane vs non-montane

${ }^{2}$ Overall $R^{2}=0.61$

${ }^{3}$ Coefficient in the linear predictor

${ }^{4} F$-test on $(1,130)$ and $(1,129)$ d.f. for mammals and birds, respectively

uncertain (Turelli et al., 2001). Thus it is not surprising that our analyses, as well as other studies, show strong correlations between high endemicity and remoteness. Areas on mountains or on islands (especially those more distant from the continent) always have the highest endemicity levels. This is simplistic, of course, because ancient biogeographic histories also contribute to the higher taxonomic distinctiveness of some units; Sri Lanka, the Western Ghats of India, New Caledonia and parts of New Guinea are ancient Gondwanaland relicts. Thus higher taxonomic distinctiveness may change the order of priority ecoregions, but the general pattern is likely to be similar.
Our analysis suggested that a plot of the logit of endemic species against species richness can discriminate between ecoregions. To obtain a simple ordering of ecoregions, we used quartiles of the two variables. This is essentially arbitrary and, if needed, more or less refined gradations are possible. By using these two variables we are able to achieve a more sophisticated ordering than the traditional technique of ordering ecoregions based only on the percentage of endemics, or any other single measure, such as Kier \& Barthlott's (2001) measure that combines endemicity and range size. For example, ecoregions 134 and 125, with high endemicity, would be classified as similar if ordering was based only on endemicity. However, ecoregion 134 has low species richness, and lies on the left of Fig. 4, whereas ecoregion 125 has high species richness and is on the right of the figure. The differences between these two ecoregions can be explained because ecoregion 134 is part of a mobile island arc and ecoregion 125 was part of the same arc but became connected with the New Guinean mainland in the Pleistocene. New Guinea is an amalgam of mainland and island fauna, and is thus complex, with a strong degree of biotic interaction (shifting selective forces and therefore more potential for evolutionary change than on tropical islands, where evolutionary change will be more or less limited to neutral drift). Our method does not preclude the need for uncovering the process that may lead to the concentrations of endemics, and more studies such as that of Mayr \& Diamond's (2001) analysis of the birds of Northern Melanesia are required.
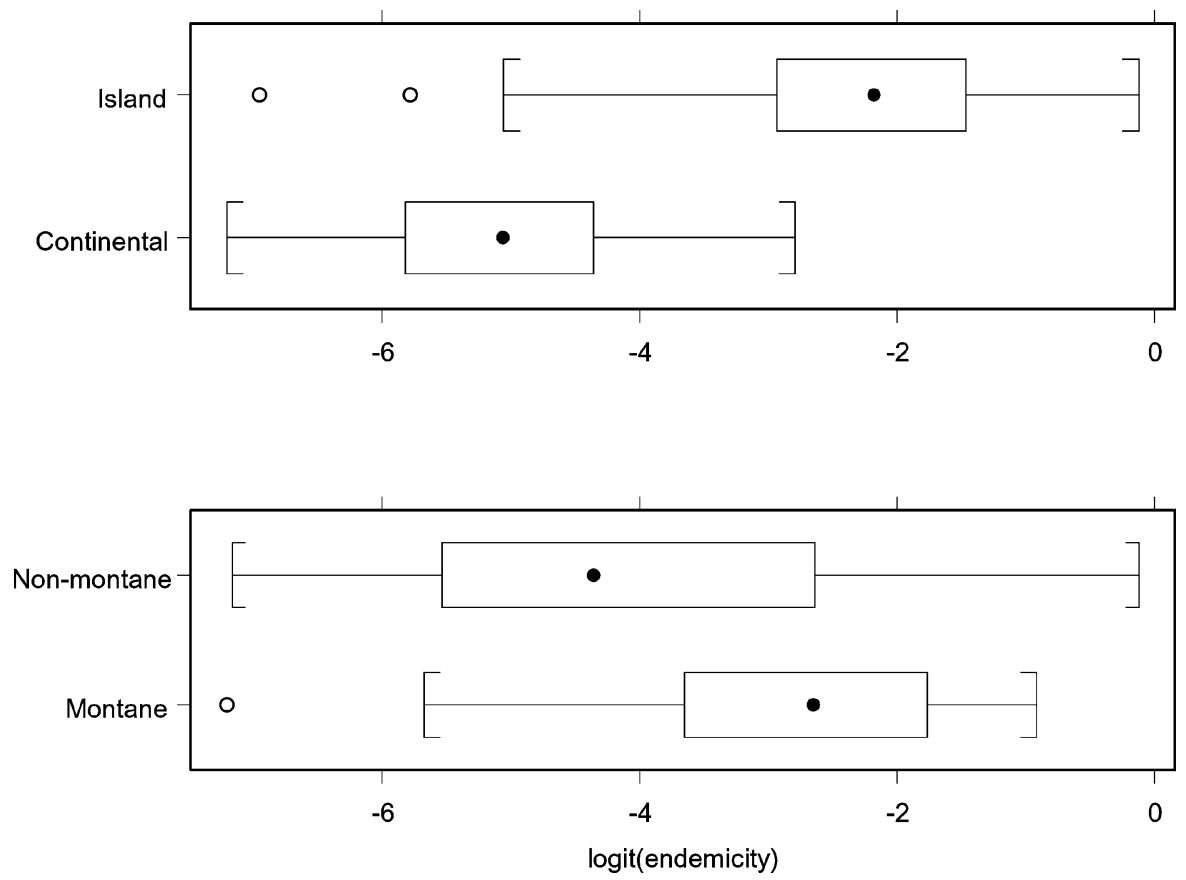

Fig. 5 Logit of endemicity, for mammals and birds combined, for island and continental, and montane and non-montane groupings. 
A possible limitation in the use of ecoregions for assessing the relationship between endemicity and richness is that ecoregion delimitation may be more precise for islands, especially for ecoregions that are true islands, but less so for continental areas. Additional principal component analyses for islands and continental areas separately show that for islands the first component $(56 \%$ of variance) is essentially endemics vs non-endemics and the second component (32\% of variance) is richness. The continental PCA produces a first component $(63 \%$ of variance) that is richness and a second component $(20 \%$ of variance) that is endemics vs non-endemics. Thus, although separate analyses for islands and continental areas explained 88 and $83 \%$ of the variance, respectively, the roles of the two scores are reversed. This is largely because the continental ecoregions are larger than island ones and richness is correlated with area. But when the analysis is undertaken after adjusting for area the first component ( $69 \%$ of variance) is richness and the second component ( $24 \%$ of variance) is endemics vs nonendemics. However, in defining areas that require conservation it is the number of endemics and not their density that is important.

Our paper emphasises endemicity and species richness as a means of selecting important speciation areas. However, our approach must be nested within a more comprehensive strategy for the region. For example, New Caledonia becomes a higher priority when taxonomic distinctiveness is considered, and rich ecoregions, such as New Guinea lowland and Borneo and Sumatran lowland and montane areas become worthy of protection. Also, the phenomena of large mammal and bird communities in Borneo and elsewhere are a critical priority that is rapidly disappearing. Thus, a set of top priority ecoregions for the area must include a representative set of hyper-rich and large mammal assemblage ecoregions as well as endemicity centres.

Further investigation of the vulnerability to extinction of species found within these areas is planned. This is important given that there are few large conservation units in the Indo-Pacific, and virtually no large reserves in lowland moist tropical forests, the most species-rich habitats (Dinerstein \& Wikramanayake, 1993; Wikramanayake et al., 2002). However, the smaller protected areas $\left(<300 \mathrm{~km}^{2}\right)$, common throughout the Indo-Pacific, may be adequate to preserve viable populations of a substantial number of endemics and conserve ecosystem diversity and ecological processes (Dinerstein \& Wikramanayake, 1993). Highlands and islands, which are the core areas of endemism, will probably benefit more from adequate protected areas networks than large continental areas, because persistence of the latter can be better achieved by wiser political decisions than through traditional reserves, as also suggested by Fjeldså et al. (1999b).
The current problem in using biogeography to aid conservation is not so much the need for more data, but for a guiding body of general theory to explain and synthesize empirical information (Mace et al., 2000). Sufficient analytical flexibility is available to be able to set the limits of areas where actions to prevent species extinctions are urgently needed. Previous analyses of areas of endemism are widely recognized as timely advances in determining where conservation needs are greatest and where potential benefits of conservation may be maximized. Our method corroborates many of the biogeographic units identified by other approaches as high priority, but our analysis also gives a sense of evolutionary potential as well as endemism; an important facet of biodiversity that has been neglected by many priority-setting approaches and analyses. Further analyses of other areas of the world, using our simple plot to highlight ecoregions of high conservation interest will allow conservation organizations to prioritize actions more succinctly and expediently.

\section{Acknowledgements}

We are most grateful to World Wildlife Fund-US for allowing us the use of their ecoregion databases. Eric Dinerstein, Eric Wikramanayake, Colby Loucks and John Lamoreux provided invaluable support and commented on a previous manuscript. Georgina Mace and Michael Usher offered stimulating discussions that were most useful in developing our ideas. David Olson and an anonymous reviewer improved the final manuscript. We thank Chris Clark for preparing the colour map.

\section{References}

Arctander, P., Johansen, C. \& Coutellec-Vreto, M-A. (1999) Phylogeography of three closely related African bovids (Tribe Alcalaphini). Molecular Biology and Evolution, 16, 1724-1739.

Balmford, A., Mace, G.M. \& Ginsberg, J.R. (1998) The challenges to conservation in a changing world: putting processes on the map. In Conservation in a Changing World (eds G.M. Mace, A. Balmford \& J.R.Ginsberg), pp. 1-28. Cambridge University Press, Cambridge, UK.

Collett, D.C. (2002) Modelling Binary Data (2nd Edition). Chapman \& Hall/CRC, London, UK.

de Klerk, H.M., Crowe, T.M., Fjeldså, J. \& Burgess, N.D. (2002) Biogeographical patterns of endemic terrestrial Afrotropical birds. Diversity and Distributions, 8, 147-162.

Dinerstein, E. \& Wikramanayake, E. (1993) Beyond "hotspots": how to prioritise investments to conserve biodiversity in the Indo-Pacific Region. Conservation Biology, 7, 53-65.

Dinerstein, E., Olson, D.M., Graham, D. Webster, A., Pimm, S., Bookbinder, M. \& Ledec, G. (1995) A Conservation Assessment of the Terrestrial Ecoregions of Latin America and the Caribbean. World Bank, Washington, DC, USA. 
Erwin, T.L. (1991) An evolutionary basis for conservation strategies. Science, 253, 750-752.

Fjeldså, J. (2000) The relevance of systematics in choosing priority areas for global conservation. Environmental Conservation, 27, 67-75.

Fjeldså, J. (2002) Polyplesis forests - vestiges of a vanishing ecosystem in the Andes. Ecotropical Monographs, 8, 111-123.

Fjeldså, J., Ehrlich, D., Lambin, E. \& Prins, E. (1997) Are biodiversity 'hotspots' correlated with current ecoclimate stability? A pilot study using the NOAA-AVHRR remote sensing data. Biodiversity and Conservation, 6, 401-422.

Fjeldså, J. \& Rahbek, C. (1997) Species richness and endemism in South American birds: implications for the design of networks of nature reserves. In Tropical Forest Remnants. Ecology, Management, and Conservation of Fragmented Communities. (eds W.F. Laurance \& R.O. Bierregard), pp. 466-484. Chicago University Press, Chicago, USA.

Fjeldså, J., Lambin, E. \& Mertens, B. (1999a) The relationship of species richness and endemism to ecoclimatic stability - a case study comparing distributions of Andean birds with remotely sensed environmental data. Ecography, 22, 63-78.

Fjeldså, J., Burgess, N., de Klerk, H., Hansen, L. \& Rahbek, C. (1999b) Are endemic bird areas the best targets for conservation? An assessment using all landbird distributions of two continents. In Proceedings of the 22nd International Ornithological Congress, Durban (eds N.J. Adams \& R.H. Snow), pp. 2271-2285. BirdLife South Africa, Johannesburg, South Africa.

García-Moreno, J. \& Fjeldså, J. (2000) Chronology and mode of speciation in the Andean avifauna. Bonner Zoologische Monographies, 46, 25-46.

Insightful Corporation (2001) S-PLUS 6 for Windows. Seattle, USA.

Jepson, P. \& Whittaker, R.J. (2002) Ecoregions in context: a critique with special reference to Indonesia. Conservation Biology, 16, 42-57.

Jetz, W. \& Rahbek, C. (2002) Geographic range size and determinants of avian species richness. Science, 297, 1548-1551.

Johnson, N. (1995) Biodiversity in the Balance: Approaches to Setting Geographic Conservation Priorities. The Biodiversity Support Program, Washington, DC, USA.

Kier, G. \& Barthlott, W. (2001) Measuring and mapping endemism and species richness: a new methodological approach and its application on the flora of Africa. Biodiversity and Conservation, 10, 1513-1529.

Krzanowski, W.J. (1988) Principles of Multivariate Analysis. Clarendon Press, Oxford, UK.

Mace, G.M., Balmford A., Boitani, L., Cowlishaw G., Dobson, A.P.D., Faith, P., Gaston, K. J., Humphries, C.J., Vane-Wright, R.I., Williams, P.H., Lawton, J.H., Margules, C.R., May, R.M., Nicholls, A.O., Possingham, H.P., Rahbek, C. \& van Jaarsveld, A.S. (2000) It's time to work together and stop duplicating conservation efforts. Nature, 405, 393.

Mayr, E. \& Diamond, J. (2001) The Birds of Northern Melanesia: Speciation, Ecology and Biogeography. Oxford University Press, Oxford, UK.

McCullagh, P. \& Nelder, J.A. (1989) Generalized Linear Models (2nd Edition). Chapman \& Hall/CRC, London, UK.

Medail F. \& Quezel P. (1997) Hot-Spots analysis for conservation of plant biodiversity in the Mediterranean Basin. Annals of the Missouri Botanical Garden, 84, 112-127.

Medail F. \& Quezel P. (1999) Biodiversity hotspots in the Mediterranean Basin: setting global conservation priorities. Conservation Biology, 13, 1510-1513.
Menard, S. (2000) Coefficients of determination for multiple logistic regression analysis. The American Statistician, 54, $17-24$.

Mittermeier, R.A., Myers, N., Thomsen, J.B., da Fonseca, G.A.B. \& Olivieri, S. (1998) Biodiversity hotspots and major tropical wilderness: approaches to setting conservation priorities. Conservation Biology, 12, 516-520.

Myers, N. (1988) Threatened biotas: "Hotspots" in tropical forests. Environmentalist, 8, 187-208.

Myers, N. (1990) The biodiversity challenge: expanded hotspot analysis. Environmentalist, 10, 243-256.

Myers, N., Mittermeier, R.A., Mittermeier, C.G., da Fonseca, G.A.B. \& Kent, J. (2000) Biodiversity hotspots for conservation priorities. Nature, 403, 853-858.

Oliver, I., Beattie, A.J. \& York, A. (1998) Spatial fidelity of plant, vertebrate and invertebrate assemblages in multiple-use forests in eastern Australia. Conservation Biology, 12, 822-835.

Olson, D.M. \& Dinerstein, E. (1998) The Global 200: A representation approach to conserving the earth's distinctive ecoregions. Conservation Biology, 12, 502-515.

Olson, D.M., Dinerstein, E., Wikramanayake, E. D., Burgess, N.D., Powell, G.V.N., Underwood, E.C., D'Amico, J.A., Itoua, I., Strand, H.E., Morrison, J.C., Loucks, C.J., Allnutt, T.F., Ricketts, T.H., Kura, Y., Lamoreux, J.F., Wettengel, W.W., Hedao, P. \& Kassem, K.R. (2001) Terrestrial ecoregions of the world: a new map of life on Earth. BioScience, 51, 933-938.

Pearson, D.L. \& Cassola, F. (1992) World-wide species richness patterns of tiger beetles (Coleoptera: Cicindelidae): indicator taxon for biodiversity and conservation studies. Conservation Biology, 6, 376-391.

Pearson, D.L. \& Carroll, S.S. (1999) The influence of spatial scale on cross-taxon congruence patterns and prediction accuracy of species richness. Journal of Biogeography, $\mathbf{2 6}$ 1079-1090.

Prendergast, J.R. (1997) Species richness covariance in higher taxa: empirical tests of the biodiversity indicator concept. Ecography, 20, 210-216.

Reid, W.V. (1998) Biodiversity hotspots. Trends in Ecology $\mathcal{E}$ Evolution, 13, 275-280.

Ricketts, T.H., Dinerstein, E., Olson, D., Loucks, C.J., Eichbaum, W.D., DellaSala, K., Kavanagh, P., Hedao, P.T., Hurley, K.M., Carney, R., Abell, M. \& Waters, S. (1999) Terrestrial Ecoregions of North America: A Conservation Assessment. Island Press, Washington, DC, USA.

Rosenweig, M.L. (1995) Species Diversity in Space and Time. Cambridge University Press, Cambridge, UK.

Spector, S. (2002) Biogeographic crossroads as priority areas for biodiversity conservation. Conservation Biology, 16, 1480-1487.

Stattersfield, A.J., Crosby, M.J., Long, A.J. \& Wege, D.C. (1998) Endemic Bird Areas of the World. BirdLife International, Cambridge, UK.

Turelli, M., Barton, N.H. \& Coyne, J.A. (2001) Theory and speciation. Trends in Ecology and Evolution, 16, 330-343.

Vane-Wright, R.I., Humphries, C.J. \& Williams, P.H. (1991) What to protect? Systematics and the agony of choice. Biological Conservation, 55, 235-254.

Venables, W.N. \& Ripley, B.D. (1999) Modern Applied Statistics with S-PLUS (3rd Edition). Springer, New York, USA.

White, F. (1983) The AETFAT chorological classification of Africa: history, methods and applications. Bulletin du Jardin Botanique de Belgique, 62, 225-281. 
Wikramanayake, E., Dinerstein, E., Allnut, T., Loucks, C.J. \& Wettengel, W. (1998) A Biodiversity Assessment and Gap Analysis of the Himalayas. Conservation Science Program, World Wildlife Fund-US Report, Washington, DC, USA.

Wikramanayake, E., Dinerstein, E., Loucks, C.J., Olson, D.M., Morrison, J., Lamorux, J., McKnight, M. \& Hedao, P. (2002) Terrestrial Ecoregions of the Indo-Pacific: A Conservation Assessment. Island Press, Washington, DC, USA.

Williams, P.H. (1998) Key sites for conservation: area-selection methods for biodiversity. In Conservation in a Changing World (eds G.M. Mace, A. Balmford \& J.R. Ginsberg), pp. 211-249. Cambridge University Press, Cambridge, UK.

Williams, P.H. \& Humphries, C.J. (1996) WORLDMAP and prioritisation for conservation: integration of systematic data for conservation evaluation. In Biodiversity Assessment: A Guide to Good Practice. (eds A.C. Jermy, D. Long, M.J.S. Sands, N.E. Stork \& S. Winser), pp. 98-99. Department of the Environment/HMSO, London, UK.

\section{Appendix}

The appendix for this article is available online at http:/ / journals.cambridge.org

\section{Biographical sketches}

Julia Fa has undertaken research in a number of conservation biology topics in Europe, Africa and South America, with a special interest in biodiversity assessment and monitoring, and endangered species management.

Robert Burn's main research interests are in applications of statistical modelling in conservation, wildlife and natural resource management. $\mathrm{He}$ is especially interested in problems arising from links between conservation and development.

Mark Stanley Price worked for many years in Africa and the Middle East, initially on antelope research, and then on the reintroduction of the Arabian Oryx into Oman. For the last 15 years he has been involved in developing and directing organizational capacity for better biodiversity conservation.

Fiona M. Underwood is a statistician with an interest in conservation and natural resource management, including adaptive monitoring strategies. 